\title{
School Autonomy and Leadership in Lithuania: Can School Leaders Help Schools to Take a Step forward?
}

\author{
Marlies Honingh ${ }^{1}$ and Jolanta Urbanovic ${ }^{2}$
}

\begin{abstract}
In the literature, the school leader (head of school) is considered a key figure in strengthening school autonomy and stimulating the further development of the school organization. To improve the functioning of school leaders a centralized assessment of all candidates who want to become school leaders was introduced in Lithuania in 2011. The findings of a qualitative study into the first experiences with the assessment provide a deeper understanding of current school leadership problems in Lithuania. A comparison of these findings with the literature on school leadership and the assumptions underlying the recently changed school-leader appointment procedure reveal the lack of a clear vision on school leadership. Some general management competences - such as managing and motivating people, making decisions and strategic thinking - are underdeveloped.
\end{abstract}

\section{Keywords}

school autonomy, school leader, assessments

\section{Introduction}

The education management system in Lithuania is gradually becoming decentralized and de-concentrated on the basis of the subsidiarity principle, as decentralization is seen as one of the key strategies to reform and reshape educational institutions. Against this background, school leadership has become a far more de-

1 Assistant Professor, Department of Political Science \& Public Administration, Nijmegen School of Management, Radboud University Nijmegen, The Netherlands.

2 Associate Professor, Department of Public Administration, Mykolas Romeris University, Vilnius, Lithuania. 
manding job (Urbanovic 2009). Today, school leaders not only need to focus on the implementation of national and local policy initiatives but are also asked to plan school activities, approve the school's educational programme and supervise its implementation, hire and dismiss teachers and identify problems and choose an adequate strategy to address them. As at least three years of teaching experience are required to become a school leader, most school leaders in Lithuania are former teachers, who lack management experience (Urbanovic 2009). Since school leadership is considered one of the key factors in stimulating a smooth process of school autonomization, it is crucial to gain an insight into expectations regarding school leadership, the formal position of school leaders and the average level of skills and expertise of school leaders and future school leaders.

In order to better understand the current position and level of skills of (future) school leaders in Lithuania we study the first experiences with the centralized assessment that was introduced in 2011 and formulated the following questions:

What is expected of school leaders if they are to stimulate the process of school autonomization? What are the first impressions and outcomes of the centralized assessment of the candidates for school leadership? Do candidates possess the competences and potential for school leadership?

\section{Policy background: decentralization and school leadership in Lithuania}

Since 1991, Lithuanian legislation has gradually been granting more rights to national and local educational institutions. By the 1990s, the first bodies of selfgovernment had been introduced. A little later, the General Concept of Education was adopted (Ministry of Culture and Education of Lithuania 1994). This concept reflected a strategy aimed at creating modern schools that share principles of humanism, democracy, renewal and commitment to Lithuanian culture and the preservation of its identity. This document also described the internal structure of the educational system, teacher-training, governance and financial principles.

Although the document was a huge step forward, the implementation process was not easy, due to some inconsistencies in the document and divergent interpretations. Reflecting on the first stage of the reforms, the OECD (1996) reported that although the conceptual foundation of the reforms was strong, there was a gap between the concepts and the reality of the implementation process. After the second reform phase, the OECD (2002) expressed its concerns about the educational management in Lithuania, acknowledging the urgent need for a better leadership and more skills at the level of schools and institutions to ensure that all those who are involved should shoulder their responsibilities. For the years 2003-2012, Želvys (2004) identified three main challenges: to improve management in education, to 
develop human resources and to get society and social partners involved in ensuring the sustainability of the reforms.

This article deals with the issue of school leadership, as it is believed that leaders do make a difference. Jackson and colleagues (2011) stated that it is apparent to all those involved in education at the national, municipal and school levels in Lithuania that the quality of leadership and management is crucial in relation to the changes required to implement the reform agenda. The Law on Education that was adopted on 25 June 1991 (amended on 4 July 2007) lays down the following key functions of principals (Snipiene and Alisauskas 2010):

- The school principal is responsible for the implementation of educational objectives in the school, implements educational policy objectives and school curricula, organizes basic and secondary school-leaving examinations, represents the school in various institutions and is responsible for the results of school activities.

- The school principal develops an annual estimate of the school's costs and income, and prepares an annual account of school activities (Annual Report).

- The school principal performs functions provided in the Regulations of the Lithuanian School of General Education.

- The school principal takes care of the school's material resources, organizes the work of support and site staff and confirms that the job descriptions are in accordance with the prescribed procedures.

Considering this colourful palette of tasks that a principal has to fulfil, a school leader can hardly be seen as a teacher with some added technical and administrative duties. Nowadays, a principal is a full-time manager of human, financial and physical resources.

In Lithuania, school leaders are chosen in public contests announced by municipalities. The municipality also appoints or dismisses a head of school. Moreover, the municipality has to approve the description of the principal's functions. It also evaluates the principal's work and activities, and organizes in-service training for principals and teaching staff. Consequently, the process of appointing school leaders is often highly politicized. Attempts have recently been made to improve the appointment procedure and make it more transparent. The competence of district candidates is now verified, and more power is given to the school board. A recent major change was the introduction in the summer of 2011 of a centralized assessment procedure to 1 ) assess whether candidates possess the competences and potential required for school leadership, 2) provide the data necessary to select the most suitable candidates for contests in educational institutions, 3) provide professional support to those who have been assessed suitable to become leaders in 
educational institutions, and 4) to gain an insight into the average level of skills and expertise of candidates for school leader (NMVA 2011).

At present, the competences of candidates who wish to participate in a contest to become a school leader have to be assessed in accordance with necessary schoolleadership competences (knowledge, attitudes and skills). These competences are assessed in addition to other qualification requirements, such as education and work experience. The methodology used is based on a multidimensional assessment of the candidates, covering the interview, task completion, problem-solving situations, group work and tests.

The policy background thus portrays a mixture of decentralization and centralization to stimulate the school-autonomization process. With regard to school leadership and appointment procedures, we noted centralized regulations - such as descriptions of the role, tasks and competences of school leaders - and the introduction of centralized assessment. Decentralization simultaneously implies the willingness of municipalities to devolve their responsibility for schools, to have a vision or at least a clear idea of what good education should look like, and to be aware of current regulations and developments in the field of education.

\section{School autonomy}

The strengthening of school autonomy is often presented in the context of decentralization policies, educational reforms, the reallocation of power and the improvement of school quality (Karsten 1998). The arguments that were used in Western European countries for increased autonomy were quite similar. They all included the benefits of increased flexibility in response to challenging circumstances, enhanced effectiveness, greater rates of innovation, higher morale and greater worker productivity (Davies and Hentschke 1994). Since the early 1980s, the strengthening of school autonomy has received considerable attention from researchers in the United States and in European countries such as Belgium, the Netherlands and the United Kingdom (Guthrie and Pierce 1990; Karsten 1998; Hooge 1998). In Central and Eastern European countries, processes of strengthening school autonomy were started more than a decade later than in Western European countries (Urbanovic 2009). Reflecting on prior school autonomy research, it is important to elaborate on two findings. First, one should keep in mind that school autonomy will always be a relative autonomy: schools are never "free", as they are often restricted by the local context (Karsten 1998). From an institutional perspective, one could argue here that "the environments of organizations are themselves organized" (Scott 1987). A school can therefore be seen as a subsystem of the broader local and national educational system. As a consequence, structural aspects of a school might be institutionalized by the environment (see Figure 1). 


\section{Figure 1}

Internal and external limits on school autonomy

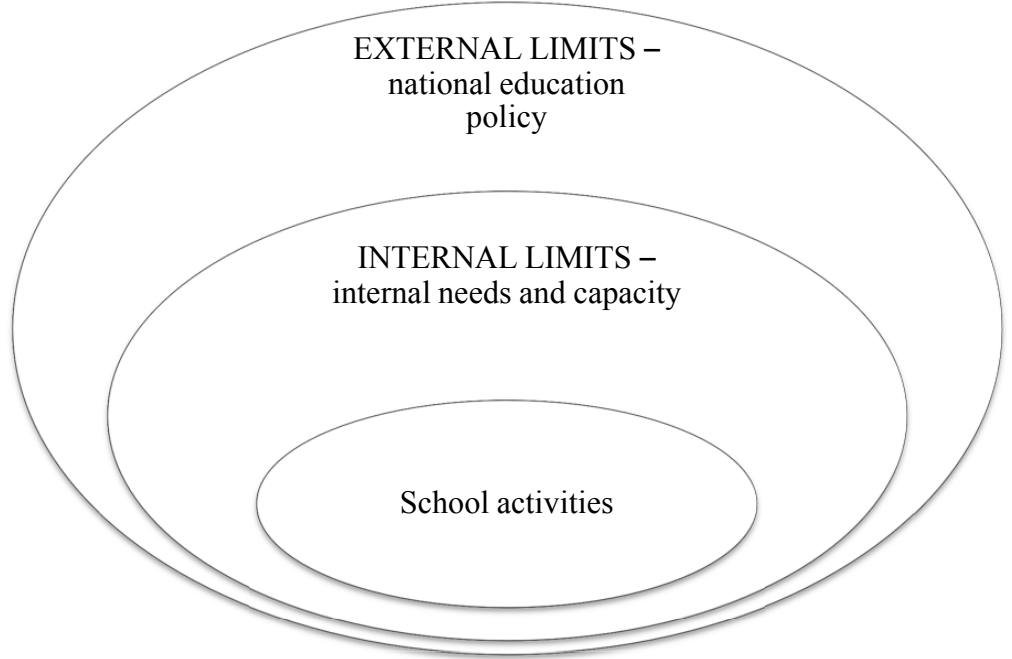

Local variation between regions, counties and schools is therefore to be expected, especially in the case of a highly decentralized system. Hannaway and Talbert (1993) specified some factors that affect schools' capacity to change, referring to the differences between urban, rural and suburban areas, local variation in the political and administrative arena, and the degree of autonomy experienced by the school principal and teams. Besides the factors on the local level that might affect the scope of autonomy and change within schools, it is also important to realize that in many countries despite policy reforms the central government still plays a crucial role in the educational system. Strict school autonomy limits are determined and based on the financial dependence on the governmental institutions, considering that the educational system receives one of the largest shares of public resources. Therefore, although a school is required to provide good quality and effective services oriented towards the client - and thus also provide a variety of educational services, create a competitive environment, support the school's self-governing and democratization, etc. - its decision-making discretion is constrained by external limits, namely government regulation and other external factors. School organizations should be considered open systems operating in the wider educational system and within their own specific geographical environment.

School autonomy implies a new equilibrium between centralized and decentralized power, policy, capacities and steering mechanisms. These theoretical notions illustrate that school autonomy cannot be studied and understood in isolation, as schools are subsystems of a wider system. As a consequence, one cannot expect simple success formulas, but only some rules of thumb and principles relat- 
ed to the implications of tensions between centralization, decentralization and the schools' capacity to change (see Nicolaidou and Petridou 2011). School organizations, school leaders, teachers, managers and all the other involved parties are thus challenged to find adequate ways and methods to cope with the specific contextual factors and external events in and around their schools. Hooge (1998) concluded in her dissertation that autonomy needs to be taken. This implies that just formally having a broader scope of autonomy will not lead to any changes. School leaders need to actively take advantage of the scope of autonomy that is granted. This perspective reveals an enormous challenge for school organizations, school leaders and teachers, as they have to put an effort into shouldering the responsibility for taking advantage of the scope of autonomy provided and for improving the school organization and the learning results.

\section{School leadership}

It is important to note that the concept of school leadership is used in a variety of ways in distinctive discourses and research traditions. Huber and Muijs (2010) presented four main perspectives, namely literature that takes 1) a theoretical perspective to consider what kind of leadership concepts and styles reflect leadership in practice, 2) a prescriptive perspective that deals with what kind of leadership should be practised, 3) an empirical perspective that investigates leadership practices within a qualitative paradigm to refine theory and develop assumptions that can be tested within a quantitative paradigm, and 4) a methodological perspective that discusses, for example, the methods of data-gathering or data analysis. In the remainder of this section, we elaborate on the first and the third research traditions. We first present some distinctive leadership concepts (though we do not aim to provide a complete overview) and then pay attention to some of the literature that takes an empirical perspective.

School leadership is looked upon as one of the key determinants of successful reform implementation, school development and school improvement. Against the background of decentralization and deregulation policies, the importance of the role of the school leader has grown, and the number of tasks and responsibilities of school leaders has inevitably multiplied (e.g. Huber and Muijs 2010). Not surprisingly, the role of school leaders, their functioning, and their contribution to school development and the improvement of student learning have been widely studied (Sleegers 1999; Caldwell and Spinks 1992; Heck and Hallinger 2005). It is assumed that successfully implemented changes are strongly related to the nature and quality of school leadership. Moreover, research supports the view that leadership has many applications and that its results are context-dependent.

General notions of school leadership emphasize that the key role of leadership is to define the ends towards which the school will strive to improve; this is some- 
times referred to as "leadership for what?" Taking this idea as a starting point is helpful in identifying and distinguishing the foci and in conceptualizing leadership. For instance, leaders of school improvement are assumed to focus on growth in student learning. While transformative school leaders try to raise the bar by referring to higher ideals, leaders and followers are united in the pursuit of higher-level goals that are common to both. Both want to shape the school in a new direction. This notion is somewhat different from that of distributed leadership, which acknowledges that the work of leading and managing schools involves multiple individuals and assumes that leadership takes shape in the interaction between school leaders, followers and aspects of their specific situation (e.g. Spillane, Halverson and Diamond 2004). Another key element is a shift away from the leader to leadership practice. Although leadership roles, structures and functions remain important, leadership practice should be seen as the most vital element (Spillane 2006). All of these conceptualizations of leadership reveal different understandings, goals and aims and seem to be developed around distinctive objectives and anchor points, such as student learning, the instruction process, vision, creating commitment, the school organizational structure, teacher development and support, and organizational improvement. Moreover, some of these notions stress leadership behaviour and practices, while others consider leadership principles to be the key. The lack of conceptual clarity illustrated in this article, challenges empirical researchers to investigate leadership effects and leadership practices.

The literature that takes an empirical perspective provides an overview of some of the differences in the actual behaviour of school leaders. Leithwood, Harris and Hopkins (2008) concluded that despite the wide variety of typologies and conceptualizations, successful leaders share four sets of leadership qualities and practices that help them to accomplish this goal. The core practices are developing a vision and setting directions, understanding and developing people, redesigning the organization, and managing the teaching and learning programme. These shared practices go beyond the somewhat artificial theoretical notions of leadership and at least combine aspects of transformative and distributive leadership.

Despite the positive expectations of leadership and the attribution of successful schools and school development to good leadership, it is necessary to remain critical. First, it is important to bear in mind that the positive attributions of leadership frequently seem to be overestimated, whilst contextual factors, such as the characteristics of the provided service, political decisions, accountability systems, institutional context and the external organizations are marginalized. In the context of schooling, Leithwood and colleagues (2008) stated that the way successful leaders apply basic leadership practices, not the practices themselves, demonstrates responsiveness to rather than dictation by the contexts in which they work. Spicker $(2012,42)$ argued that in much of the literature there seems to be a sense that whatever the context and whatever the framework, encouraging leadership, training people to be leaders and developing the skills of leadership are bound to improve 
their effectiveness. The weight that is attributed to leadership should therefore be debated. In accordance with another understanding, Leithwood and colleagues (2002 in Mulford 2003) pointed out that evidence of the effects on school leaders of decentralization is associated with a radically increased emphasis on budgetary considerations, and that less attention to providing leadership in matters related to curriculum and instruction greatly increases demands and the need for more attention to time management. As a consequence, it seems a little naïve to overestimate the positive contribution of school leadership.

On a more fundamental level, Spicker (2012) argued that it is not self-evident that the exercise of "leadership" is desirable, appropriate or even permissible in public services. Services such as education and healthcare are not allowed to fail, as they have to provide a consistent, reliable service. He stated that some management techniques are highly contestable in these sectors. Moreover, there is a real danger that these techniques and activities distract attention from the purposes and values of public services (Spicker 2012; Leithwood et al. 2002).

These strongly contrasting expectations of the benefits and contributions of school leadership raise a question concerning the role of school leaders in the school autonomization process in general and in Lithuania more specifically.

\section{Methods}

The data we collected using qualitative research approaches stem from document analyses and face-to-face interviews. We conducted the semi-structured interviews in March-April 2012. The interview guide was semi-structured, and the respondents had the freedom to elaborate on certain topics if they wanted to. The interviews were audio recorded, literally transcribed in Lithuanian and then translated into English. The interviews lasted 40-90 minutes. Some responses could not be given directly and were later provided by email.

We interviewed three Lithuanian government officials and two employees of the National School Assessment Agency. The three officials were responsible for reforming and implementing the school principal selection and appointment procedure. The representatives from the assessment agency had been involved in creating and developing the appointment and assessment procedure.

We developed an interview guide for these interviews. It contained seven questions. The first questions were formulated around findings presented in the school-leadership literature in order to establish whether and, if so, which notions of and expectations regarding leadership are covered by the centralized assessment instrument. Second, we included in the interview guide conditions to enhance the autonomization process, such as those identified by Urbanovic (2011), to allow us to examine whether requirements to further enhance leadership quality are met in Lithuania. Furthermore, we asked the respondents about the quality of school 
managing as a process, whether the centralized assessment helps to ensure that capable school leaders are appointed, and what kind of leadership they consider to be necessary in Lithuania. We also included some technical questions about the assessment procedure, the specific topics and competences that are assessed, and the assessment experience. In some cases it was useful to ask the respondents a couple of additional questions.

\section{Results}

To gain an insight into some of the main and shared management problems in Lithuanian schools, we asked the respondents to reflect on current management problems. All of the respondents emphasized the impact of path dependency (postSoviet experience) on school management. Two stated that each school had its own specific experiences and problems:

School leadership trends are very different and heavily dependent on the head's person and functioning. Moreover, managers as well as school leaders all have a distinctive perception of their role. (M2)

... it can be said that school leaders vary widely in the perception of their tasks and duties. Some see themselves as an administrator, property manager or director, while others see themselves as a strategist - it is very important to the modern school that the school leader is a strategist. (M3)

Another stressed that:

... the management culture in Lithuania is rather young and still developing. This is especially the case in public-sector organizations. It is sometimes even thought that schools do not need management at all. This might be explained by the fact that some people consider management and administration to be almost identical. Moreover, since administration does not seem to have an extensive added value, people are negative about management. I expect good governance to have a positive effect and to gain momentum. (M1)

\section{The type of school leadership required in Lithuania}

In response to our request to describe the kind of leadership that is needed in Lithuania, one respondent stated: "The school head must be a leader who can lead and/or bring together a collective" (A2). Another stressed the need for a vision: 
A head of school - a school leader - needs to have a vision: they are a leader first of all. If they are an effective leader, then they are able to carry out certain tasks and perform efficiently. They will be able to share their leadership and delegate tasks if necessary, and are therefore leaders in the true, general sense of the word. Being a leader is fundamentally different from being a head or a manager. (M2)

Two of the respondents also referred to the conditions that are necessary for effective school leadership:

One of the crucial conditions is to increase independence [autonomy]; if there is no independence, then there is no leader but a decision implementer. Formally, the scope or room of independence is provided, and whoever wants it, can use it while the one who does not want it, can always find a reason not to use it. (M1)

In Lithuania, schools are rather autonomous in comparison to other countries. If the head wants to take responsibility, he has the opportunity to do so. Of course, there are differences, because municipalities differ and do not always delegate similar tasks and functions. (M2)

The unwillingness to self-manage might be associated with a lack of capacity, which becomes particularly evident when management functions are decentralized: "Autonomy is significantly influenced by legislation, but it is much more influenced by perceptions, competences and thinking." (M1)

Another respondent referred to the inevitable link between autonomy and the level of responsibility that comes with it:

... surveys show that people like to see themselves as independent and free. But when they are asked who should be responsible for a range of activities, they say: the ministry or the municipal department of education. These people just want freedom, but do not seem to want the responsibility that comes with it, which means that there are no real managerial relations. (M3)

\section{The new appointment procedure}

Due to the perceived difficulties of enhancing the quality of educational leadership, ideas were generated to improve the appointment procedure for school principals and to improve the management skills of heads of schools. To raise the bar, the heads of schools are required to have qualifications that ensure that they can contribute to enhancing school autonomization. Nevertheless, one of the respondents 
stated that some improvement is necessary and that: "It would be appropriate to make part of the assessment the self-assessment of current heads." (A2)

According to the respondents, there were a number of reasons to implement a new procedure for competence assessment:

One of the reasons to change the procedure of leader appointment was to help to choose leaders that would be able to independently assess problems and make appropriate decisions in all kinds of specific situations. (M1)

This means that it is about: "... selecting people who really have the potential to become good school leaders, thus, our goal is to see that potential." (A1) Or in other words:

The main purpose of the changes in the certification of potential school leaders is to shift from paperwork to performance evaluation. It will not be just a competence assessment, but will be mainly based on activities, and what someone has done and is potentially able to do. (A1)

As in all professions, the quality level of the work depends on the qualities of the appointee and whether he or she improves and learns during the work. The appointment system was barely able to gain an insight into the candidates' competences and abilities to improve. The appointment system was built around a review of the formal criteria. (M1)

The new assessment procedure depoliticizes and decreases the number of school leaders who are appointed because they are part of a network or circle of acquaintances, as candidates are now selected for their abilities. (M2)

The argument about reduction of politicization is also clear. (M1) Another strategic motive is to give the market a signal that in order to participate in the selection of heads in the contest, competences are very important. If people know that their competences will be assessed, they will try to improve them. Thus, potential candidates will be able to work in advance to prepare themselves for the assessment. This seems to be a positive mechanism that also enhances the performance of educators and their awareness of the competences that are needed to become a school leader. (M1) 
Another strategic reason for the assessment is that:

The assessment procedure is also a signal to people that the bar is high because the number of schools is decreasing, and we thus have the ability to select the best candidates. (M3)

The above response is linked to other motives to commence with the assessment: such an assessment or evaluation can be seen as a first step towards stimulating further education. Moreover:

If a candidate passes the national competence assessment procedure, he or she has the opportunity to participate in any contest to become a head of school. (A1)

The new assessment system allows people with less experience to qualify for management positions and enables people from the business sector to occupy the post of head of school. (A1)

The National School Evaluation Agency also has a support function, although schools might see the assessments more as a judgment, rather than as a kind of support. (M1)

\section{The assessment}

We wanted to explore what kind of leadership is assessed, what kind of leadership is stimulated by the assessment and what ideas about leadership underlie the assessment. Reflecting on policy documents that lay down the official requirements that school leaders must meet and the aspects that are included in the centralized assessment, we concluded that both a university degree and leadership competences are required. The assessment indicates whether a candidate is expected to have the competences that are needed to succeed in professional school leadership activities. The expectations regarding educational leadership that are assessed during the central assessment include competences and knowledge that cover strategic thinking and people and operational management skills (such as personal effectiveness, strategic thinking, communication and competences in the field of change, and people management). The respondents provided information about trends they observed regarding the strengths and weakness of candidates and the success rates. In general, it seems that some candidates who just want to give the assessment a try have lower assessment scores than those who were motivated.

Those who passed the assessment first were motivated because they entered a specific contest. Their pass rates were high, while those who went to the evaluation just to have a go had lower scores. (M2) 
To assess competences, various school-life situations are presented to the candidates to assess whether they are able to make rapid and rational decisions. (A1)

Although not much experience with the assessment has been gained, we can already identify some trends. The results show that candidates face the most difficulties in directing people. According to the representatives of the assessment agency, more that $40 \%$ of all candidates failed this part of the assessment. One respondent stated that candidates also struggle with personnel management and inspiring others:

We have noticed the lack of ability to motivate, inspire, reveal the potential of and educate people. This is often based on the idea that quality and responsibility for completing an assigned task is "self-evident". (A1)

Furthermore, about half of the candidates do not obtain the minimum points in the strategic-thinking and change-management-skills assessment:

Applicants often lack the ability to objectively assess the situation, analyze it in terms of possible causes and consequences, and think it over in a broader context. Situational decisions are taken on the basis of experience and prejudices. It turns out to be difficult to tackle tasks that require logical thinking skills. (A1)

According to one respondent, one of the other benefits of the assessment is the possibility to identify whether perceptions, attitudes and actions are consistent:

Evaluation shows, among other things, the necessity of flexibility in solving problems, targeted objective-seeking, and the ability and willingness to take responsibility for the final result. Expressed attitudes frequently do not correspond to the actual actions or decisions. Applicants lack organizational and time management skills. (A1)

According to the representatives of the assessment agency, about one-third of the candidates score below the minimum on leadership development and learning competence.

Despite the criticism and the assessment difficulties, the respondents seemed to be optimistic about the assessment by stating that it could help in finding and selecting the right people - that is, people who will be able to manage and lead a school - and in stimulating learning. This idea is also supported by the fact that the most valued competence during the assessment was the ability to learn (A1). Most candidates had the ability to absorb and integrate new information, apply the acquired knowledge in practice and apply appropriate and varied methods of learning, and they had the ability and willingness to share knowledge, experiences, etc. 
Thus, the introduction of a centralized procedure for assessing candidates' competence seems to have increased the likelihood that head teacher posts will be filled by people who are able to manage people, organize a team, think strategically and take responsibility, and who have confidence in school-culture formation.

The procedures for competence assessment were especially criticized because the evaluation procedure is successfully passed by only $50 \%$ of the candidates. However, the respondents stressed that more time is needed before judging the assessment, since the appointment procedure is still under development. Therefore, the new regime and procedure should be given time. The implementation of the new regime was difficult due to some dominant elements of the bureaucratic system:

People in the education system found - and still find - it diffcult to evaluate themselves. All kinds of documents are used for evaluations; thus, there is a tendency to think that if someone has a document, then there is a basis for an evaluation. Some candidates become indignant and ask how it is possible that they have a document, and yet are told that they did not pass the assessment. (A1)

Another point of criticism is the fact that candidates are not accustomed to the idea that the assessment takes 6-8 hours. Even the head teachers who had successfully completed the evaluation process considered this a handicap. They contended that they had studied all night, while this had not been necessary because the assessment focuses on behaviour patterns (i.e. competences), which cannot be learned from textbooks.

The assessment focuses on how one behaves in certain situations, how one takes decisions, and how one communicates and collaborates. (M3)

\section{Analysis}

An analysis of the results revealed that although the respondents have had general management problems, there were some common and shared difficulties. That $40 \%$ of the candidates have difficulty in managing people and that motivating people has turned out to be very hard for most candidates, are clear indicators of a common lack of competences.

Another common shortcoming is the extent to which school leaders take responsibility for decision-making. The respondents reported that they expect a large proportion of school leaders not to make use of the scope of autonomy they formally have. The discrepancy between the formal scope of autonomy and the autonomy that is used in daily practice reveals that school leaders do not take responsibility for the full range of managerial tasks they have to fulfil. This deficit cannot be un- 
derstood in isolation, since the results also show that many school organizations suffer from a lack of managerial relations and leadership experience, which in turn is related to the fact that Lithuania has a rather young management culture. To complicate matters further, the need for management and managerial relations is not clear to all those that are involved, since some people even doubt the added value of management in the educational system - and this doubt will not make it any easier to stimulate managerial relations and the willingness of those who are in charge to shoulder their responsibility.

Despite the variety of expectations people have about leadership, most of the respondents emphasized the need to be a true leader who has a vision and takes responsibility for the implementation of school autonomy. What we should expect from such a leader in daily practice, however, remains somewhat vague. It can therefore be doubted whether there is enough knowledge available about the precise content and challenges a school leader faces in daily practice.

\section{Discussion and conclusion}

As the school principal is often the main initiator in fostering school change and enhancing the school autonomization processes, our focus was on school leaders. To gain an insight into school leadership in Lithuania and the contribution of school leaders to the fostering of change, we posed the following research questions:

What is expected of school leaders if they are to stimulate the process of school autonomization? What are the first impressions and outcomes of the centralized assessment of the candidates for school leadership? Do candidates possess the competences and potential for school leadership?

First, this study showed the perceived need in Lithuania to improve the functioning of school leaders. Many heads of schools are considered not to function adequately as they do not contribute enough to the processes of school autonomization, they lack a clear idea of their tasks and responsibilities, and they have difficulty in taking responsibility. These impressions are in line with an earlier study by Urbanovic (2011), who also concluded that school leaders who lack some managerial competences are more afraid of taking responsibility for decision-making.

The lack of decision-making ability and leadership experience might be associated with the experience of education management in many European countries (see also Wenzel 1997), especially in CEE countries where education policy was historically characterized as a management system based on centralization, bureaucracy and control. The control of such a system was oriented towards regulation: laws, decisions and directions. This means that schools were totally dependent: their leaders were only the implementers of centrally made decisions, who did not need any special abilities to make decisions on the organization of services. This historical background needs to be taken into account in trying to understand the current 
state of the development of school leadership in Lithuania. Some of the respondents directly referred to local and contextual factors that still affect the perceptions of the leadership and functioning of their school leaders.

To complicate matters further, the local context of schools, the school communities and the involvement of interest groups prompts the expansion of school independence and making school activities more public. But if the decision-making process includes more and more individuals and members of various organizations and groups, all with different needs and hopes, the school-management process becomes even more complex. Therefore, the role of the school leader becomes more important. The school leader must operate as a leader and negotiator and collaborate with social partners to achieve common goals in order to build trust and commitment.

The clearly felt need to improve the functioning of school leaders led to the introduction in 2011 of a centralized assessment of all candidates who want to become school leaders. This assessment is based on testing competences and is a novelty in the appointment of school leaders in Lithuania. The first experiences with the assessment confirm the described worries about the level of competences of school leaders. Only $50 \%$ of the candidates passed the assessment. Furthermore, the results of the assessment show that $40 \%$ of the candidates have difficulty managing people. Candidates also struggled with motivating and inspiring people, thinking logically and strategically and taking rational decisions.

The assessment instrument also shows that there is no such thing as a clear notion of educational leadership underlying the assessment instrument. Comparing the elements in the assessment with the concepts of school leadership, such as distributive leadership or transformational leadership, we are forced to conclude that the assessment covers a wide variety of general competences ranging from logical thinking, decision-making and personnel effectiveness, to motivating people. The literature on school leadership often stresses the need for alignment between a vision on learning, education, and the design of learning processes and school management. Of course, although this is not a problem in itself, it is remarkable that we did not find a clear idea or notion of educational leadership that embodies the further development of school leaders.

Despite the difficulties and challenges, the newly developed assessment system could help in selecting people who have the competence to mobilize people to further develop the country's schools. The assessment clearly indicates that attempts are being made to raise the bar in terms of leadership competences.

\section{References}

Caldwell, B. J. and J. M. Spinks. 1992. Leading the Self-Managing School. London: Falmer. 
Davies, B. and G. C. Hentschke. 1994. "School Autonomy: Myth or Reality - Developing an Analytical Taxonomy." Educational Management \& Administration 22(2), 96-103.

Guthrie, J. W. and L. C. Pierce. 1990. "The International Economy and National Education Reform: A Comparison of Education Reforms in the United States and Great Britain." Oxford Review of Education 16(2), 179-203.

Hannaway, J. and J. Talbert. 1993. "Bringing Context into Effective Schools Research: Urban and Suburban Differences." Education Administration Quarterly 29, 164- 186.

Heck, R. H. and P. Hallinger. 2005. "The Study of Educational Leadership and Management: Where does the Field Stand Today?" Educational Management, Administration \& Leadership 33(2), 229-244.

Hooge, E. 1998. Ruimte voor beleid. Amsterdam: Universiteit van Amsterdam.

Huber, S. and D. Muijs. 2010. "School Leadership Effectiveness: The Growing Insight in the Importance of School Leadership for the Quality and Development of Schools and their Pupils." In S. Huber (ed.). International Perspectives on School Leadership. Oxford, UK, Springer, 57-77.

Jackson, C., S. Blandford, E. Pranckuniene and M. Vildziuniene. 2011. "Time for Leaders: Lithuania's Response to Changing Leadership and Learning in their Schools." Professional Development in Education 37(5), 701-719.

Karsten, S. 1998. "School Autonomy in the Netherlands: The Development of a New Administrative Layer." Educational Management Administration \& Leadership 26(4), 395.

Leithwood, K., A. Harris and D. Hopkins, D. 2008. Seven Strong Claims about Successful School Leadership. School Leadership \& Management: Formerly School Organisation, 28(1), 27-42.

Leithwood, K., D. Jantzi and R. Steinbach. 2002. "School Leadership and the New Right.” In K. Leithwood, P. Hallinger, G. Furman, P. Gronn, J. MacBeath, B. Mulford and K. Riley (eds). Second International Handbook of Educational Leadership and Administration. Norwell, MA: Kluwer, 849-880.

Ministry of Culture and Education of Lithuania. 1994. General Concept of Education in Lithuania. Vilnius: Leidybos Centras.

Mulford, B. 2003. "Balance and Learning: Crucial Elements in Leadership for Democratic Schools." Leadership and Policy in Schools 2(2), 109-124.

Nicolaidou, M. Petridou, A. 2011. "Evaluation of CPD Programmes: Challenges and Implications for Leader and Leadership Development." School Effectiveness and School Improvement 22(1), 51-85. 
NMVA. 2011. "Vadovų vertinimas" [Assessment of heads]. Nacionalinè mokyklų vertinimo agentūra [National Agency of School Assessment]. Available at http://www.nmva.smm.lt/ltl/content/informacija-0 (last accessed 20 june 2013.

OECD. 2002. Reviews of National Policies for Education: Lithuania. Paris: OECD Publications.

OECD. 1996. Secondary Education Systems in PHARE countries: Survey and Project Proposals. Paris: OECD Publications.

Sleegers, P. J.C. 1999. Leidinggeven aan leren. Nijmegen: Katholieke Universtiteit Nijmegen.

Snipiene, R. and Alisauskas, R. 2010. Comenius Report on Lithuania: A European Qualification Network for Effective School Leadership. Lithuania: Ministry of Education and Science.

Spicker, P. 2012. "Leadership': A Perniciously Vague Concept." International Journal of Public Sector Management 25(1), 34-47.

Spillane, J. P. 2006. Distributed Leadership. San Francisco, CA: Jossey-Bass.

Spillane, J. P., R. Halverson and B. Diamond. 2004. "Towards a Theory of Leadership Practice: A Distributed Perspective." Journal of Curriculum Studies 36(1), 3-34.

Urbanovič J. 2011. Mokyklos autonomijos valdymo modelis [The Model of School Autonomy Management]. Doctoral dissertation, Vilnius: Mykolas Romeris University.

Urbanovic, J. 2009. "Aspects of Decentralization in Management Reforms of the Education System in Lithuania." Public Policy and Administration 30, 102-113.

Wenzel, H. 1997. "Autonomia szkoły a reforma oświaty." In Z. Radwan (ed.). Rozwój organizacyjny szkoły. Radom: Instytut Technologii Eksploatacji, 97-112.

Želvys, R. 2004. "Development of Education Policy in Lithuania during the Years of Transformations." International Journal of Educational Development 24(5), $559-571$. 